\title{
REVIEW
}

\section{Tumour necrosis factor (TNF) in psoriatic arthritis: pathophysiology and treatment with TNF inhibitors}

\section{P J Mease}

Ann Rheum Dis 2002;61:298-304

High levels of proinflammatory cytokines, including tumour necrosis factor (TNF), have been detected in psoriatic skin lesions and joints of patients with the inflammatory disease. Early results of treatment of psoriatic arthritis and psoriasis with TNF neutralising agents are encouraging, but whether these agents will be able to improve long term outcomes, such as disability, is not yet known.

Agents that neutralise tumour necrosis factor (TNF), a proinflammatory cytokine, have recently been shown to relieve the signs and symptoms of psoriatic arthritis (PsA). ${ }^{12}$ The mechanism by which these agents provide this benefit is related to the role of TNF in this chronic inflammatory arthritis. Psoriatic arthritis virtually always occurs in patients with psoriasis, which is present in $1-3 \%$ of the general population. ${ }^{3}$ From $5 \%$ to over $30 \%$ of patients with psoriasis develop PsA. $^{3-7}$ Although PsA was once considered benign, recent studies have shown that even actively treated patients can have significant joint damage and deformity. ${ }^{8}$ One study showed that $57 \%$ of patients had erosive arthritis, and 19\% displayed moderate to severe functional impairment. ${ }^{9}$ The pathogenesis of PsA remains unclear; however, evidence suggests that disease progression is predicted by significant inflammation early in the course of the disease. ${ }^{10}$

\section{FEATURES AND CONSEQUENCES OF PSORIASIS AND PsA}

The skin lesions of the major form of psoriasis, plaque psoriasis, are typically erythematous papules topped by a silvery white scale. Other disease variants include guttate, pustular, and erythrodermic psoriasis. Generally, psoriasis begins to appear in patients between the ages of 20 and 50 years. The papules coalesce to form plaques of varying shapes and patterns, especially on the elbows, knees, scalp, groin, and nails.

Although the cause and pathogenesis of psoriasis are unknown, genetic factors, immunological factors, and environmental agents are believed to have a role. ${ }^{11}$ Certain HLA antigens are associated with psoriasis, particularly HLA-Cw6 in white subjects and HLA-Al and HLA-DRl in Asians, but considerable genetic heterogeneity exists in these loci among patients with psoriasis. ${ }^{11}$ Activation of T lymphocytes, antigen presenting cells, and adhesion molecules through autoimmune mechanisms is believed to play a key, probably overlapping, role in the epidermal hyperproliferation of psoriasis. ${ }^{12}$ The cytokines produced in response to immune activation are also critical contributors to disease pathogenesis. For example, proinflammatory cytokines such as TNF are found in high levels in the skin lesions and plasma of patients with psoriasis. ${ }^{13}$ In some cases, psoriasis may be triggered by environmental stimuli, such as streptococcal or other infection, trauma, or certain drugs. ${ }^{11}{ }^{14}$

"Multiple genetic, immunological, and environmental factors have been implicated in the pathogenesis of PsA."

Why a subset of patients with psoriasis also experience PsA joint manifestations is not known. In approximately $75 \%$ of patients with PsA, the appearance of skin lesions precedes arthritic symptoms. About $10-15 \%$ of patients have simultaneous onset of psoriasis and PsA, and another $10-15 \%$ show signs of characteristic PsA before developing psoriasis. The onset of PsA is typically between 30 and 55 years of age, but a juvenile form may strike children younger than 16. Men and women are equally affected.

PsA may have a variety of clinical features that can overlap with one another in presentation. Patients with PsA may present with asymmetrical oligoarthritis (fewer than five affected joints); symmetrical or asymmetrical polyarthritis (five or more affected joints); distal interphalangeal (DIP) joint involvement; arthritis mutilans, a rare, severely deforming type of arthritis (fig 1); and an ankylosing spondylitis-like inflammatory arthritis affecting the spine. ${ }^{3516}$ Polyarthritis in PsA may be similar to rheumatoid arthritis (RA) and is asymmetrical in about half of cases. ${ }^{15}$ The onset and relative severity of PsA may not correlate with the onset and severity of psoriasis in any given patient. ${ }^{17}$

Because of its heterogeneous nature, PsA may be difficult to differentiate from other forms of inflammatory arthritis. Most patients are seronegative for rheumatoid factor, so PsA is classified as a seronegative spondyloarthropathy, a category that includes ankylosing spondylitis, Reiter's disease, and enteropathic arthropathies. However, rheumatoid factor is sometimes found in patients

Abbreviations: DIP, distal interphalangeal; DMARDs, disease modifying antirheumatic drugs; IM, intramuscular; MTX, methotrexate; NSAIDs, non-steroidal

anti-inflammatory drugs; PASI, Psoriasis Area and Severity Index; PsA, psoriatic arthritis; RA, rheumatoid arthritis; SSZ, sulfasalazine; TNF, tumour necrosis factor 


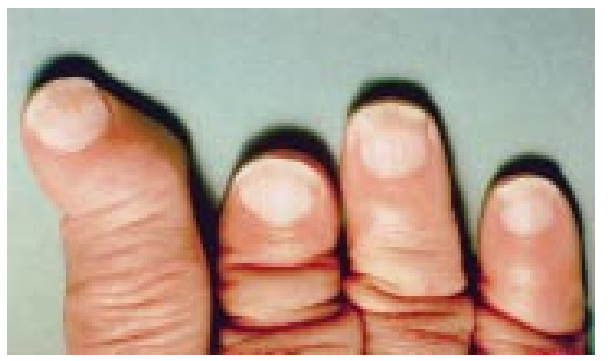

Figure 1 Distal interphalangeal joint involvement in the fingers of a patient with arthritis mutilans, a severe form of psoriatic arthritis.

with PsA, which complicates the task of distinguishing between PsA and RA, especially as PsA may occur before the appearance of psoriasis symptoms. ${ }^{18}$ Five clinical subgroups of PsA have been proposed by Moll and Wright: $(a)$ arthritis of DIP joints, $(b)$ arthritis mutilans, (c) symmetrical arthritis similar to RA but with negative rheumatoid factor, $(d)$ asymmetrical pauciarticular arthritis with dactylitis, and (e) ankylosing spondylitis with or without peripheral arthritis. ${ }^{10} 16$ Unfortunately, the sensitivity of these criteria is low, ${ }^{19}$ leading to suggestions that the criteria should be updated. ${ }^{19} 20$ The definitive diagnosis of PsA remains a complex issue.

PsA can result in severe deformity and functional impairment. In one prospective study, $57 \%$ of patients were found to have erosive arthritis, resulting in moderate to severe functional impairment in $19 \%$, at the time of referral to the rheumatology clinic. ${ }^{9}$ Inflammation early in the course of the disease appears to be a significant predictor of disease progression. A 14 year prospective study found that a high number of effusions upon first presentation at a PsA clinic correlated with future progression of joint damage, and a low erythrocyte sedimentation rate correlated with little disease progression. ${ }^{10}$ The majority of PsA-induced joint damage appears to occur early in the course of disease, as indicated by the fact that the rate of disease progression slows over time. ${ }^{8}$ Although the underlying damage may occur early, the course of PsA is typically one of cumulatively increasing numbers of affected joints over time. A prospective evaluation found that the proportion of patients with five or more damaged joints doubled from $19 \%$ to $41 \%$ during the five year study. ${ }^{8}$

\section{PATHOGENESIS}

As with psoriasis, multiple genetic, immunological, and environmental factors have been implicated in the pathogenesis of PsA. Immunogenetic phenotyping has disclosed associations between PsA and several HLA loci, but in some cases, studies have yielded conflicting results. ${ }^{18}$ Currently, evidence appears to be strongest for involvement of the HLA-Cw6 loci in PsA. A comparison of patients with familial or sporadic PsA found that HLA-Cw6 was more common in familial cases. Other loci, including HLA-B7, -B27, -B39, -DR4, -DR7, and -DQ3, had similar frequencies in these two groups. ${ }^{21} \mathrm{~A}$ specific allele of this locus, HLA-CW*0602, was found to be more common in patients with PsA than in disease-free controls. ${ }^{22}$ A polymorphism at position -238 in the promoter of the TNF gene is also associated with PsA and with juvenile onset psoriasis. ${ }^{23}$

Immunological factors appear to be particularly important in the pathogenesis of PsA. An understanding of the mechanisms by which these factors contribute to the disease is evolving. The inflammatory nature of this disease is apparent in the presence of cellular infiltrates in skin and joint lesions and the deposition of immunoglobulin molecules in the skin and synovial membrane. ${ }^{15}$ Needle biopsies of synovial membrane from patients with PsA show intense mononuclear cell infiltrates of both $\mathrm{T}$ and $\mathrm{B}$ cells, ${ }^{24}$ particularly CD8+ T cells. ${ }^{25}$ Although the membrane is highly vascularised, the lining layer is only two to three cells deep, much less than that

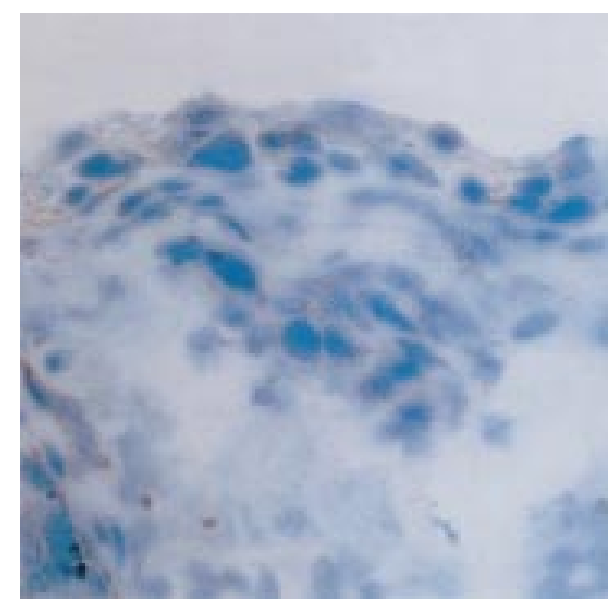

Figure 2 Tumour necrosis factor (TNF) expression in a synovial membrane section from an affected joint of a patient with a severe form of psoriatic arthritis, arthritis mutilans (original magnification $\times 600$ ). The section was stained with a monoclonal antibody to TNF. Reproduced from Danning et al, $2000^{27}$ with permission.

seen in patients with RA. This difference may be attributed to reduced trafficking of immune cells in the joints of patients with PsA as compared with those with RA, possibly owing to reduced expression of the adhesion molecule E-selectin in the synovial membranes of patients with PsA. ${ }^{24}$

Cytokines derived primarily from monocytes/macrophages, such as TNF, interleukin 1 , interleukin 6 , and interleukin 8 , are raised in the synovial fluid and membranes of affected joints (fig 2) and in synovial explants. ${ }^{136-28}$ Although most studies have found that the levels of these cytokines are somewhat lower than those found in the joints of patients with RA, the overall pattern of cytokine expression is similar, suggesting that these intracellular messengers may be general mediators of joint inflammation and destruction. ${ }^{26}{ }^{27}$ Cytokines produced by the $\mathrm{T}$ helper $\mathrm{l}$ (Thl) subpopulation (for example, interleukin 2, interferon $\gamma$, and lymphotoxin $\alpha$ ) are also raised in the synovial fluids and tissues of patients with PsA. ${ }^{28}$ These results suggest that complex interactions between $T$ cells and monocytes/macrophages help drive the pathogenesis of PsA. ${ }^{28}$

As with psoriasis, environmental factors, such as viral and bacterial infections, have been implicated in the pathogenesis of PsA. ${ }^{11}$ High levels of antibodies to a streptococcal exotoxin and to peptidoglycans, cell wall antigens found in Staphylococcus aureus and certain streptococcal strains, have been detected in patients with PsA. However, it is unclear whether these bacteria have a causal role. ${ }^{30}$ A retroviral-like particle originally isolated from patients with psoriasis has been implicated in the pathogenesis of PsA, but the evidence for this association remains unconvincing. ${ }^{30}$ The role of trauma in PsA has also been considered. To date, however, no epidemiological studies have been conducted to examine this association. $^{30}$

\section{TREATMENT}

Treatment for PsA depends on the extent of joint manifestations. Mild joint symptoms may respond to physiotherapy and non-steroidal anti-inflammatory drugs (NSAIDs). ${ }^{31}$ More severe disease is likely to require treatment with corticosteroids or disease modifying antirheumatic drugs (DMARDs). Methotrexate (MTX) is the most commonly used DMARD in the treatment of PsA (Chang DJ, personal communication). Other choices include cyclosporin A, gold, sulfasalazine, azathioprine, and antimalarial drugs. ${ }^{32}$ The use of these agents is largely predicated on the knowledge of their effectiveness in RA. A small number of randomised controlled 


\begin{tabular}{|c|c|c|c|c|}
\hline Agents & Regimen/comparator(s) & $\mathrm{n}$ & $\begin{array}{l}\text { Statistically significant } \\
\text { clinical effects }\end{array}$ & References \\
\hline Methotrexate & Pulse $7.5-15 \mathrm{mg} / \mathrm{wk}$ v placebo & 37 & $\begin{array}{l}\text { Small improvements in } \\
\text { doctor assessments of } \\
\text { disease activity and area } \\
\text { covered by psoriatic lesions }\end{array}$ & $\begin{array}{l}\text { Willkens RF et al, } \\
1984^{33}\end{array}$ \\
\hline $\begin{array}{l}\text { IM gold } \\
\text { thiomalate }\end{array}$ & $\begin{array}{l}50 \mathrm{mg} \text { once } / \mathrm{wk} v 3 \mathrm{mg} \text { bid } \\
\text { auranofin } v \text { placebo }\end{array}$ & 82 & $\begin{array}{l}\text { Improvements in joint pain } \\
\text { and ESR at } 23 \text { and } 24 \\
\text { weeks for IM gold } v \\
\text { placebo, no significant } \\
\text { changes for auranofin }\end{array}$ & $\begin{array}{l}\text { Palit J et al, } \\
1990^{34}\end{array}$ \\
\hline Sulfasalazine & $500 \mathrm{mg}$ qid $v$ placebo & 30 & $\begin{array}{l}\text { Improvements in arthritis } \\
\text { symptoms at } 1 \text { and } 6 \text { mos, } \\
\text { no effect on psoriasis }\end{array}$ & $\begin{array}{l}\text { Farr } M \text { et al, } \\
1990^{35}\end{array}$ \\
\hline Sulfasalazine & $500 \mathrm{mg}$ qid $v$ placebo & 221 & $\begin{array}{l}\text { Slightly better overall } \\
\text { response in arthritis than } \\
\text { with placebo }\end{array}$ & $\begin{array}{l}\text { Clegg DO et al, } \\
1996^{36}\end{array}$ \\
\hline Etanercept & $25 \mathrm{mg} \mathrm{sc}$ twice/wk $v$ placebo & 60 & $\begin{array}{l}\text { Improvements in joint pain } \\
\text { and swelling at } 4,8 \text {, and } \\
12 \text { weeks; greatly reduced } \\
\text { psoriasis* }\end{array}$ & $\begin{array}{l}\text { Mease PJ et al, } \\
2000^{1}\end{array}$ \\
\hline
\end{tabular}

studies have been conducted to assess the efficacy and safety of these agents in the treatment of PsA (table 1). In a 1984 double blind, placebo controlled trial of low dose pulse MTX (7.5-15.0 mg/wk) in 37 patients, doctor assessment of arthritis activity and skin surface area with psoriasis responded marginally more favourably to MTX treatment than to placebo in patients with PsA. However, there was no significant difference between MTX and placebo in patient assessment, joint pain/tenderness and swelling count or score, grip strength, morning stiffness, or skin erythema, inflammation, or scaling. Patients receiving MTX had a small but statistically significant increase in serum total bilirubin, but no patients withdrew from the study because of adverse drug effects. ${ }^{33}$ A double blind comparison of auranofin, intramuscular (IM) gold thiomalate, and placebo in 82 patients with PsA demonstrated significant improvements in Ritchie articular index, visual analogue pain score, and erythrocyte sedimentation rate at 12 and 24 weeks in patients receiving IM gold, but no significant changes were seen in those receiving auranofin. IM gold was shown to be safe and more effective than auranofin in patients who were followed up for six months. ${ }^{34}$

Sulfasalazine (SSZ) has also been tested in PsA. A double blind, placebo controlled study of SSZ in 30 patients with PsA showed greater improvement in patients in the SSZ group than in those receiving placebo. SSZ treatment was discontinued in $26 \%$ of patients because of mild side effects. ${ }^{35}$ However, no remission or exacerbation of psoriasis was observed. A 1996 Veterans Affairs Cooperative Study of 221 patients, in which SSZ was compared with placebo in the treatment of PsA, concluded that SSZ $2000 \mathrm{mg} /$ day is well tolerated and may be more effective than placebo in the treatment of patients with this disease ${ }^{36}$ The difference in treatment response, which was defined by a predetermined set of criteria (table 2 ), was statistically significant ( SSZ 57.8\% v placebo $44.6 \%$; $\mathrm{p}=0.05$ ). However, none of the individual criteria achieved significance. ${ }^{36}$ Cyclosporin has been shown to be significantly effective in the treatment of psoriasis, ${ }^{37}$ but only a single abstract has been published on the use of this drug in patients with PsA. This report concerned a controlled study that showed present, but "less dramatic, changes" in PsA (Doyle D, personal communication).

A large scale, multinational trial is currently under way to test the efficacy of leflunomide in PsA. This agent, which acts at the level of pyrimidine synthesis and affects T cell proliferation, has efficacy in RA similar to that of SSZ and MTX. ${ }^{38}$

\section{Table 2 Psoriatic Arthritis Response Criteria*}

Improvement in two of the following four criteria, one of which must be tender or swollen joint score:

Doctor global assessment ( 1 unit on 0-5 Likert scale)

Patient global assessment ( 1 unit on 0-5 Likert scale)

Tender joint score (30\% improvement)

Swollen joint score (30\% improvement)

No worsening in any criteria

*From Clegg et al, 1996. ${ }^{36}$

However, at the time of writing, results of leflunomide treatment in PsA are not yet available.

A 1999 survey of American rheumatologists indicated that most have the impression that the effectiveness of azathioprine and antimalarial drugs (for example, hydroxychloroquine) in PsA is slight. ${ }^{32}$ Indeed, published evidence for the efficacy of these drugs consists of little more than case series and opinion, ${ }^{39-42}$ and reports of psoriasis exacerbation due to hydroxychloroquine have appeared..$^{43}$

To date, no evidence exists showing that DMARDs prevent progression of joint damage in PsA. Indeed, a 24 month study of patients with PsA found no difference in radiographic damage scores between MTX treated patients (doses ranging from $5 \mathrm{mg} / \mathrm{wk}$ to $20 \mathrm{mg} / \mathrm{wk}$ ) and retrospectively matched historical controls. ${ }^{44}$ However, true evaluation of DMARD effectiveness in slowing joint damage in PsA awaits larger controlled trials.

The current difficulty in effectively treating all patients with PsA has spurred the quest for other agents that improve pain and function, slow or prevent disease progression, and improve patient wellbeing. Much attention has been focused on agents that inhibit the activity of proinflammatory cytokines, which are believed to play a primary role in joint destruction. The first such agents to be examined in clinical trials exert their therapeutic activity by neutralising TNF and are available for clinical use, having shown significant clinical efficacy in RA.

\section{TNF: A PROINFLAMMATORY CYTOKINE}

Tumour necrosis factor is produced primarily by macrophages in response to injury or infection. This cytokine displays multiple biological activities. At the cellular level, TNF has roles in lymphocyte and neutrophil adhesion, decreased haemopoiesis, stimulation of collagenase and prostaglandin $\mathrm{E}_{2}$ 


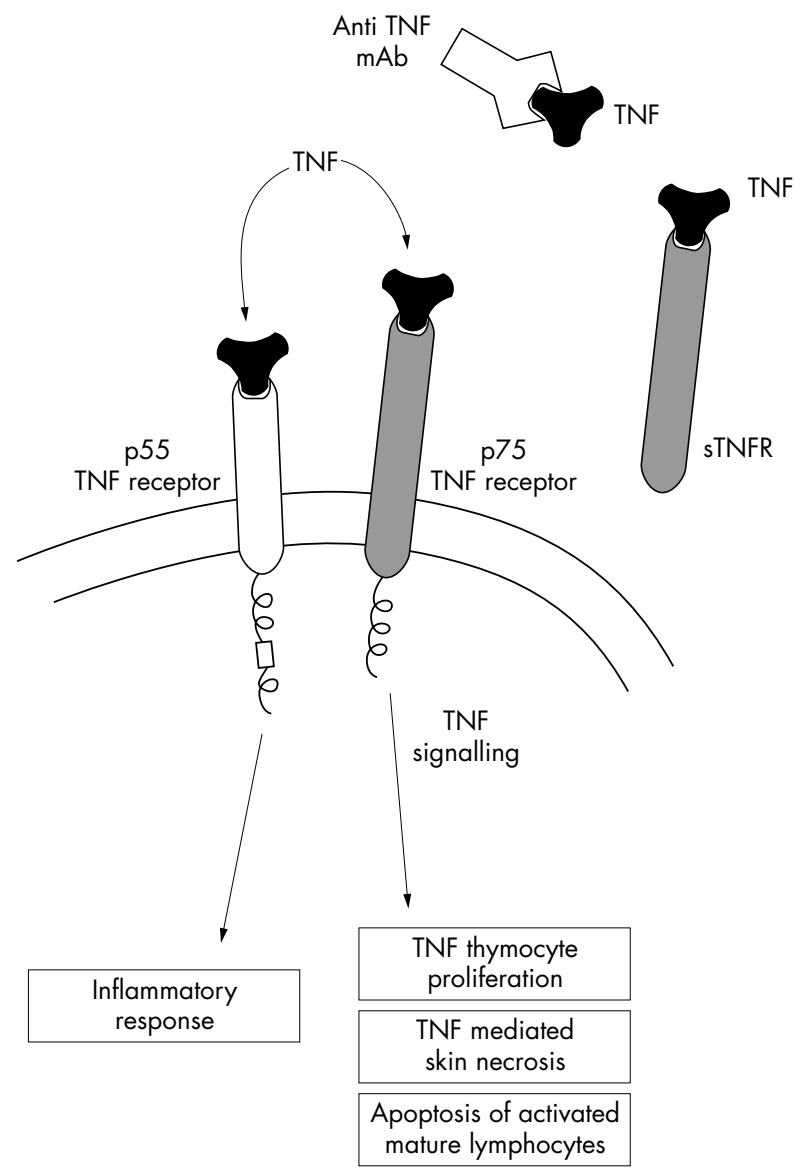

Figure 3 Neutralisation of TNF by soluble TNF receptors (sTNFR) or anti-TNF monoclonal antibody ( $\mathrm{mAb}$ ) prevents TNF binding to either the p55 or the 775 receptors. ${ }^{47}{ }^{64-67}$

synthesis, and the production of other cytokines; at the tissue level, TNF participates in proteoglycan breakdown, acute tubular necrosis, and bone resorption. ${ }^{45}{ }^{46}$ Clinically, TNF activity plays a part in anorexia, weight loss, fever, haemorrhage, and inflammation. ${ }^{45}$

Intracellular signalling mediated by TNF occurs through interactions with cell bound TNF receptors. These receptors are present on almost all cells. The two distinct but structurally similar TNF receptors are designated p55 and p75. These receptors form dimers on the cell surface, where they bind a trimeric TNF molecule, thus initiating signal transduction (fig 3). ${ }^{45}$ The receptors also bind to and are activated by lymphotoxin $\alpha$, a cytokine that is structurally similar to TNF and has similar biological activities. ${ }^{46}$ Although the p55 and p75 receptors appear to have some overlapping functions, studies in TNF-receptor deficient knockout mice indicate that the p75 receptor has a more significant role than p55 in suppressing TNF mediated inflammatory responses. ${ }^{47}$

\section{"Inhibitors of TNF ameliorate the symptoms and disease activity of certain inflammatory forms of arthritis"}

Soluble forms of both the p55 and p75 TNF receptor have been identified in the sera and synovial fluids of patients with rheumatic diseases and are believed to act as endogenous TNF inhibitors. ${ }^{48-50}$ Analyses of synovial fluids have shown that the levels of p55 and p75 soluble TNF receptors are significantly higher in patients with PsA than in those with osteoarthritis but lower than in patients with RA. ${ }^{50}$

Although TNF plays a vital part in protecting the body from infection and injury, this cytokine has also been implicated in an array of human diseases. In particular, TNF is believed to have a primary role in inflammatory conditions (for example, RA and other autoimmune diseases), infection related damage (septic shock, toxic shock syndrome), cachexia, and heart failure. ${ }^{5152}$

The evidence for the role of TNF in inflammatory forms of arthritis is particularly strong. Although undetectable in the sera of healthy humans, TNF is present at high levels in the joint fluid and tissue of patients with RA and PsA. ${ }^{26354}$ Furthermore, TNF is known to mediate a number of biological processes that can result in joint damage. These include stimulation of bone resorption, inhibition of bone formation, inhibition of synthesis of proteoglycan, and induction of collagen and cartilage degrading metalloproteinases and prostaglandin $\mathrm{E}_{2}{ }^{55-58}$ The best evidence for the role of TNF in joint destruction, however, is the ability of TNF neutralisers to ameliorate the symptoms and disease activity of certain inflammatory forms of arthritis and to slow or halt joint destruction.

\section{CLINICAL USE OF TNF BLOCKING AGENTS}

Two TNF neutralising agents-etanercept and infliximabhave proved highly effective in treating inflammatory disorders such as RA. ${ }^{59}$ These agents differ in both their mechanisms of action and their form of administration. Etanercept is a recombinant dimeric form of the soluble TNF p75 receptor. Like the endogenous soluble receptor, etanercept binds tightly to TNF and to lymphotoxin $\alpha$, rendering them biologically inactive. Etanercept was the first biological agent to be approved for the treatment of RA. It is indicated for reducing signs and symptoms and inhibiting structural damage in patients with moderately to severely active RA. Etanercept is also approved for the treatment of refractory juvenile RA. ${ }^{60}$ This agent is given by subcutaneous injection, twice weekly.

The other available TNF inhibitor, infliximab, is a chimeric (mouse-human) monoclonal antibody that binds and neutralises TNF. Originally approved for treatment of Crohn's disease, infliximab is now also approved for treatment of RA when given concomitantly with MTX. ${ }^{61}{ }^{62}$ Infliximab should be used in combination with MTX to avoid the development of antibodies to infliximab and the potential diminution of clinical response. It is given by intravenous infusion. Both etanercept and infliximab have been shown to slow joint damage in patients with RA and can thus be considered true DMARDs (Finck B, personal communication; Lipsky P, personal communication). Other TNF neutralising agents, including a fully human monoclonal antibody to TNF, are in the early stages of development.

\section{POTENTIAL FOR TNF NEUTRALISING AGENTS IN THE TREATMENT OF PSA}

The primary treatment goals for PsA are to reduce joint inflammation and pain, maintain mobility, and prevent deformity. The apparent involvement of TNF in PsA joint damage suggests that, as with RA, agents that neutralise TNF may have therapeutic benefit in patients with PsA. Accordingly, we initiated a placebo controlled, randomised clinical study in which 60 patients with PsA received either etanercept ( $25 \mathrm{mg}$ subcutaneously twice weekly) or placebo. ${ }^{1}$ Patients in this study had had psoriasis for a mean of approximately 20 years and PsA for a mean of 11.5 years. Patients achieving partial benefit with MTX were allowed to continue with it; this subgroup of $47 \%$ of patients was evenly randomly allocated to the placebo or etanercept groups. Background use of NSAIDs or prednisone $10 \mathrm{mg} /$ day was allowed. All other DMARDs and topical medicines for psoriasis were discontinued.

The primary arthritis efficacy response measure was the Psoriatic Arthritis Response Criteria (PsARC) (table 2). The secondary arthritis measures were the ACR 20, 50, and 70 


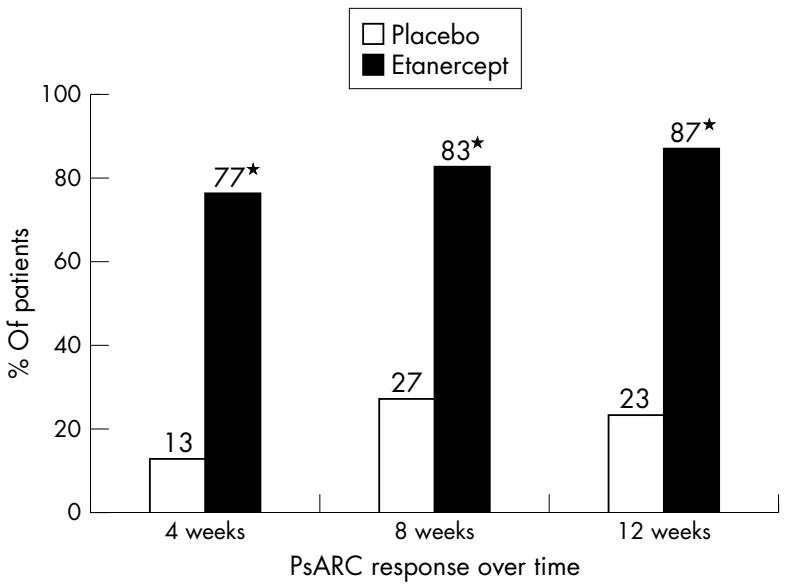

Figure 4 Clinical response as assessed by Psoriatic Arthritis Response Criteria (PsARC) in patients with PsA treated with etanercept or placebo. Adapted from Mease 2000' with permission.

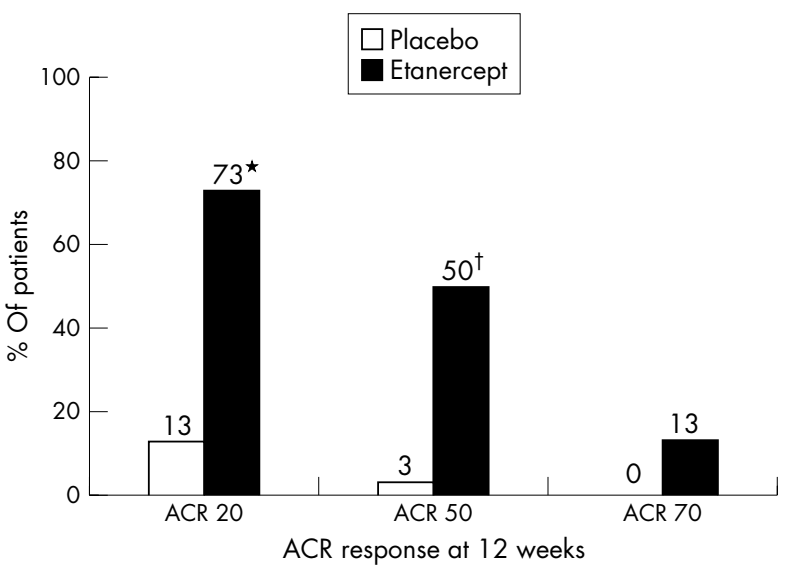

Figure 5 Clinical response as assessed by American College of Rheumatology (ACR) criteria in patients with PsA treated with etanercept or placebo. ACR 20,50, and 70 responses are defined as $\geqslant 20 \%, \geqslant 50 \%$, and $\geqslant 70 \%$ reductions, respectively, in tender and swollen joint counts and in three or more of the following: patient pain assessment, patient global assessment, doctor global assessment, patient disability assessment, and $C$ reactive protein level. Adapted from Mease 2000' with permission.

responses, modified for use in PsA. At the study end point ( 12 weeks), $87 \%$ of etanercept treated patients were responders, compared with $23 \%$ of placebo treated patients (fig 4 ). The effect was rapid; by four weeks, $77 \%$ of patients receiving etanercept qualified as responders. At 12 weeks, four patients ( $13 \%)$ had no tender joints and seven patients (23\%) had no swollen joints. Similar dramatic responses were noted when ACR 20, 50, and 70 criteria were applied (fig 5). There was no statistically significant difference between the joint response of patients who were receiving MTX and those who were not.

Of the 60 patients with active PsA, 38 had $\geqslant 3 \%$ body surface area affected with psoriasis, the minimum requirement for the evaluation of skin response. Evaluating dermatologists employed two skin response scoring systems, the Psoriasis Area and Severity Index (PASI) and the target lesion score. The PASI is a composite measure based on scale, erythema, and induration that is weighted by severity and body surface area. ${ }^{63}$ The target lesion score is derived from the amount of scale, erythema, and plaque of a single, preselected lesion.

The median improvement in PASI score in etanercept treated patients $(n=19)$ at three months was $46 \%$, compared with $9 \%$ in the placebo group $(n=19)$. Twenty six per cent of patients treated with etanercept had a 75\% PASI response, representing nearly complete resolution of skin disease. The median improvement in target lesion score was 50\% in the etanercept group and $0 \%$ in the placebo group. There was no difference in skin response whether the patient was receiving MTX or not.

In this three month trial, etanercept was well tolerated. No patient in the etanercept group discontinued treatment. Twenty per cent of the etanercept treated patients experienced mild injection site reactions that resolved with continued use without interruption. No other adverse events occurred significantly more often in the etanercept group than in the placebo group. Thus, this study showed that etanercept treatment resulted in significant improvement in PsA and psoriasis and was safe during this period of observation. All patients in the trial were eligible to receive etanercept in an open fashion for six months, during which time concomitant drugs could be adjusted. Further improvement in both joint and skin disease was noted. In those patients receiving etanercept in the first three months, those achieving an ACR 20 response increased from $73 \%$ to $87 \%$ between three and nine months, and those achieving an ACR 70 response increased from 13\% to 33\%. The median PASI score in those patients increased from $46 \%$ to $62 \%$. Of those receiving MTX, $25 \%$ were able to discontinue and $43 \%$ were able to decrease MTX. Of those receiving prednisone, $44 \%$ discontinued the drug and $67 \%$ decreased it.

A study of nine patients with severe, resistant PsA reached similar conclusions about the use of etanercept in patients with PsA (Yazici Y, personal communication). In this study, etanercept was added to the current treatment regimen (three patients were receiving MTX and one each cyclosporin A, sulfasalazine, prednisone, minocycline, acitretin, and mycophenolate mofetil). After an average follow up of four months, five patients were free of arthritis, and the remainder experienced only mild joint pain. Two patients returned to work, five were able to enjoy recreational sports again, and four were able to reduce concomitant drugs, including prednisone.

An additional study of 12 patients with DMARD refractory PsA also indicated that etanercept is effective and well tolerated for the treatment of PsA. Before the study, all DMARDs except MTX $\leqslant 20 \mathrm{mg}$ were discontinued. Patients received etanercept $25 \mathrm{mg}$ subcutaneously twice a week. Mean (SD) PASI scores decreased from 8 (6) at baseline to l (1) after treatment with etanercept. Ten of 12 patients experienced complete resolution of skin involvement and were able to resume previous work and leisure activities. MTX doses were significantly reduced in those patients, and MTX was eventually discontinued in four patients. Two of the patients in the study did not improve and continued to require high doses of MTX and other anti-inflammatory drugs (Cuellar ML, personal communication).

Infliximab has also been tested in the treatment of PsA (Antoni C, personal communication). In a small open label study of six patients with severe PsA despite MTX treatment, infliximab ( $5 \mathrm{mg} / \mathrm{kg}$ once every two weeks) was added to the MTX regimen, and responses were evaluated for six weeks. At the study end point, swollen joint counts improved by $88 \%$ and tender joint counts by $86 \%$. Magnetic resonance imaging data suggested that inflammation was reduced.

A study of the one year outcome of 10 patients with severe PsA treated with infliximab and MTX, conducted in the same centre as the open label study, showed that this regimen was effective over one year. Patients were treated with $5 \mathrm{mg} / \mathrm{kg}$ of infliximab at weeks 0,2 , and 6; most also received concomitant DMARD treatment (MTX, $\mathrm{n}=7 ; \mathrm{SSZ}, \mathrm{n}=1$ ). After 10 weeks of treatment all patients showed reduced signs and symptoms of PsA and decreased serological activity. Infliximab treatment was then individualised to meet patient need. At week 10, one patient stopped treatment for personal reasons. He had a five month remission, after which he experienced mild PsA activity. Infliximab was discontinued in three patients after three, seven, and eight weeks because 
remission was achieved, and in one patient after eight months because of a new pregnancy and an infusion reaction. Follow up at one year showed continued ACR 70 response in these five patients. The remaining four patients continued infliximab treatment of $3-4 \mathrm{mg} / \mathrm{kg}$ at lengthened intervals $\geqslant 8$ weeks, and three of these patients (with ACR 70 response at week 10) showed an ACR 50 response upon evaluation at one year. The remaining patient (ACR 50 response at week 10) experienced a flare after nine months of infliximab treatment, but an ACR 50 response was achieved again with increased doses of infliximab and four week infusion intervals (Dechant C, personal communication).

Another open label study included 21 treatment resistant patients with various subtypes of spondyloarthropathy; nine of these patients had PsA. ${ }^{2}$ As in the previous study, these patients received three infusions of $5 \mathrm{mg} / \mathrm{kg}$ infliximab at 0,2 , and 6 weeks. Although concomitant NSAIDs and corticosteroids were allowed, treatment with MTX and other DMARDs was not: all DMARDs were discontinued at least four weeks before the study began. ${ }^{2}$ Rapid and significant improvements in articular symptoms were noted throughout the treatment period and were maintained for the additional six weeks that the patients were monitored after the last infusion. By study end point, the median swollen joint count had decreased from 3.5 to 0 in the 21 patients. The authors reported no significant differences among the spondyloarthropathy subtypes, but data for each subtype were not presented separately. Psoriasis symptoms were evaluated in eight of the patients with PsA. Median values of the PASI score decreased by $85 \%$ during treatment. ${ }^{2}$

\section{CONCLUSIONS}

Early results with TNF neutralising agents in the treatment of PsA and psoriasis are encouraging. The symptomatic improvements seen in these studies have been profound and sustained, and adverse effects have been minimal. Inhibitors of TNF thus appear to have excellent potential for treating PsA and psoriasis. Whether these agents will be able to improve long term outcomes, such as disability, is not yet known. The ability of etanercept and infliximab to slow joint damage in patients with RA has been convincingly demonstrated; hopefully, these findings will prove true in PsA as well. Given the close association between early signs of inflammation and subsequent joint damage in patients with PsA, early control of inflammation through the use of TNF neutralisers may have a positive impact on future functional ability.

The clinical benefits of TNF inhibitors in patients with PsA and psoriasis raise the question as to whether other cytokine inhibitors will have similar effects. Agents that neutralise interleukin 1 are currently being tested in clinical trials of RA, and may also be useful in the treatment of PsA and psoriasis. As our understanding of the pathophysiology of PsA and psoriasis improves, the options for treating these difficult and often devastating conditions may also expand.

\section{REFERENCES}

1 Mease PJ, Goffe BS, Metz J, Vanderstoep A, Finck B, Burge DJ. Etanercept in the treatment of psoriatic arthritis and psoriasis: a randomised trial. Lancet 2000;356:385-90.

2 Van den Bosch F, Kruithof E, Baeten D, De Keyser F, Mielants H, Veys $E M$. Effects of a loading dose regimen of three infusions of chimeric monoclonal antibody to tumour necrosis factor alpha (infliximab) in spondyloarthropathy: an open pilot study. Ann Rheum Dis 2000;59:428-33.

3 Oriente CB, Scarpa R, Pucino A, Oriente P. Psoriasis and psoriatic arthritis: dermatological and rheumatological co-operative clinical report. Acta Derm Venereol (Stockh) 1989;146(suppl):69-71.

4 Roenigk HH Jr, Epstein E, Mailbach HI. Skin manifestations of psoriasis and eczematous psoriasis: maturation. In: Roenigk HH Jr, ed. Psoriasis. New York, NY: Marcel Dekker, 1991:3-7.

5 Espinoza LR, Cuellar ML, Silveira LH. Psoriatic arthritis. Curr Opin Rheumatol 1992;4:470-8.
6 Shbeeb M, Uramoto KM, Gibson LE, O'Fallon WM, Gabriel SE. The epidemiology of psoriatic arthritis in Olmsted County, Minnesota, USA, 1982-1991. J Rheumatol 2000;27:1247-50.

7 Scarpa R, Oriente P, Pucino A, Torella M, Vignone L, Riccio A, et al. Psoriatic arthritis in psoriatic patients. Br J Rheumatol 1984;23:246-50.

8 Gladman DD, Stafford-Brady F, Chang C-H, Lewandowski K, Russell ML. Longitudinal study of clinical and radiological progression in psoriatic arthritis. J Rheumatol 1990;17:809-12.

9 Torre Alonso JC, Rodriguez Perez A, Arribas Castrillo JM, Ballina Garcia J, Riestra Noriega JL, Lopez Larrea C. Psoriatic arthritis (PA): a clinical, immunological and radiological study of 180 patients. $\mathrm{Br} \mathrm{J}$ Rheumatol 1991;30:245-50.

10 Gladman DD, Farewell VT, Nadeau C. Clinical indicators of progression in psoriatic arthritis: multivariate relative risk model. J Rheumatol 1995;22:675-9.

11 Espinoza LR, van Solingen R, Cuellar ML, Angulo J. Insights into the pathogenesis of psoriasis and psoriatic arthritis. Am J Med Sci 1998;316:271-6.

12 Ortonne J-P. Recent developments in the understanding of the pathogenesis of psoriasis. Br J Dermatol 1999; 140(suppl 54):1-7

13 Ettehadi P, Greaves MW, Wallach D, Aderka D, Camp RDR. Elevated tumour necrosis factor-alpha (TNF- $\alpha$ ) biological activity in psoriatic skin lesions. Clin Exp Immunol 1994;96:146-51

14 Wolf R, Ruocco V. Triggered psoriasis. Adv Exp Med Biol 1999;455:221-5

15 Gladman DD. Psoriatic arthritis. Rheum Dis Clin North Am 1998;24:829-44

16 Moll JMH, Wright V. Psoriatic arthritis. Semin Arthritis Rheum 1973;3:55-77

17 Cohen MR, Reda DJ, Clegg DO. Baseline relationships between psoriasis and psoriatic arthritis: analysis of 221 patients with active psoriatic arthritis. J Rheumatol 1999:26:1752-6.

18 McGonagle D, Conaghan PG, Emery P. Psoriatic arthritis: a unified concept twenty years on [published erratum appears in Arthritis Rheum 1999;42:1997]. Arthritis Rheum 1999;42:1080-6.

19 Fournié B, Crognier L, Arnaud C, Zabraniecki L, Lascaux-Lefebvre V, Marc V, et al. Proposed classification criteria of psoriatic arthritis. A preliminary study in 260 patients. Rev Rhum Engl Ed 1999:66:446-56.

20 Marsal S, Armadans-Gil L, Martinez M, Gallardo D, Ribera A, Lience E. Clinical, radiographic and HLA associations as markers for different patterns of psoriatic arthritis. Rheumatology (Oxford) 1999;38:332-7.

21 Rahman P, Schentag CT, Beaton M, Gladman DD. Comparison of clinical and immunogenetic features in familial versus sporadic psoriatic arthritis. Clin Exp Rheumatol 2000;18:7-12.

22 Gladman DD, Cheung C, Ng C-M, Wade JA. HLA-C locus alleles in patients with psoriatic arthritis (PsA). Hum Immunol 1999;60:259-61

23 Hamilton ML, Gladman DD, Shore A, Laxer RM, Silverman ED. Juvenile psoriatic arthritis and HLA antigens. Ann Rheum Dis 1990;49:694-7.

24 FitzGerald $O$. Advances in understanding and novel therapeutic targets in inflammatory arthritis. Ir J Med Sci 1995;164:4-11.

25 Costello P, Bresnihan B, O'Farrelly C, FitzGerald O. Predominance of CD8+ T lymphocytes in psoriatic arthritis. J Rheumatol 1999;26:1117-24.

26 Partsch G, Steiner G, Leeb BF, Dunky A, Bröll H, Smolen JS. Highly increased levels of tumor necrosis factor- $\alpha$ and other proinflammatory cytokines in psoriatic arthritis synovial fluid. J Rheumatol 1997;24:518-23

27 Danning CL, Illei GG, Hitchon C, Greer MR, Boumpas DT, Mclnnes IB. Macrophage-derived cytokine and nuclear factor $\mathrm{\kappa B}$ p65 expression in synovial membrane and skin of patients with psoriatic arthritis. Arthritis Rheum 2000;43:1244-56.

28 Ritchlin C, Haas-Smith SA, Hicks D, Cappuccio J, Osterland CK, Looney RJ. Patterns of cytokine production in psoriatic synovium. J Rheumatol 1998;25:1544-52.

29 Partsch G, Wagner E, Leeb BF, Bröll H, Dunky A, Smolen JS. T cell derived cytokines in psoriatic arthritis synovial fluids. Ann Rheum Dis 1998;57:691-3

30 Abu-Shakra M GD. Aetiopathogenesis of psoriatic arthritis. Rheumatol Rev 1994:3:1-7.

31 Pringle F. A multidisciplinary approach to psoriatic arthropathy. Community Nurse 1999;5:21-2.

32 Chang DJ. A survey of drug effectiveness and treatment choices in psoriatic arthritis [abstract]. Arthritis Rheum 1999;42(suppl 9):S372.

33 Willkens RF, Williams HJ, Ward JR, Egger M, Reading JC, Clements PJ, et al. Randomized, double-blind, placebo controlled trial of low-dose pulse methotrexate in psoriatic arthritis. Arthritis Rheum 1984;27:376-81.

34 Palit J, Hill J, Capell HA, Carey J, Daunt SO, Cawley MI, et al. A multicentre double-blind comparison of auranofin, intramuscular gold thiomalate and placebo in patients with psoriatic arthritis. Br J Rheumatol 1990;29:280-3.

35 Farr M, Kitas GD, Waterhouse L, Jubb R, Felix-Davies D, Bacon PA. Sulphasalazine in psoriatic arthritis: a double-blind placebo-controlled study. Br J Rheumatol 1990;29:46-9.

36 Clegg DO, Reda DJ, Mejias E, Cannon GW, Weisman MH, Taylor T, et al. Comparison of sulfasalazine and placebo in the treatment of psoriatic arthritis: a Department of Veterans Affairs Cooperative Study. Arthritis Rheum 1996;39:2013-20.

37 Ellis CN, Fradin MS, Messana JM, Brown MD, Siegel MT, Hartley AH, et al. Cyclosporine for plaque-type psoriasis. N Engl J Med 1991;324:277-84.

38 Sharp JT, Strand V, Leung H, Hurley F, Loew-Friedrich I, on behalf of the Leflunomide Rheumatoid Arthritis Investigators Group. Treatment with 
leflunomide slows radiographic progression of rheumatoid arthritis: results from three randomized controlled trials of leflunomide in patients with active rheumatoid arthritis. Arthritis Rheum 2000;43:495-505.

39 Hacker SM, Ramos-Caro FA, Ford M, Flowers FP. Azathioprine: a forgotten alternative for treatment of severe psoriasis. Int J Dermatol 1992;31:873-4

40 Le Quintrec JL, Menkes CJ, Amor B. [Severe psoriatic rheumatism. Treatment with azathioprine. Report of 11 cases]. Rev Rhum Mal Osteoartic 1990;57:815-19.

41 Sayers ME, Mazanec DJ. Use of antimalarial drugs for the treatment of psoriatic arthritis. Am J Med 1992;93:474-5.

42 Jones G, Crotty M, Brooks P. Interventions for treating psoriatic arthritis (Cochrane review). In: The Cochrane Library, Issue 1. Oxford: Update Software, 2001.

43 Luzar MJ. Hydroxychloroquine in psoriatic arthropathy: exacerbations of psoriatic skin lesions. J Rheumatol 1982;9:462-4.

44 Abu-Shakra M, Gladman DD, Thorne JC, Long J, Gough J, Farewell VT. Longterm methotrexate therapy in psoriatic arthritis: clinical and radiological outcome. J Rheumatol 1995;22:241-5.

45 Beutler BA. The role of tumor necrosis factor in health and disease. J Rheumatol 1999;26(suppl 57):16-21.

46 Bazzoni F, Beutler B. The tumor necrosis factor ligand and receptor families. N Engl J Med 1996;334:1717-25.

47 Peschon JJ, Torrance DS, Stocking KL, Glaccum MB, Otten C, Willis CR. TNF receptor-deficient mice reveal divergent roles for p55 and p75 in several models of inflammation. J Immunol 1998;160:943-52.

48 Cope AP, Aderka D, Doherty M, Engelmann H, Gibbons D, Jones AC, et al. Increased levels of soluble tumor necrosis factor receptors in the sera and synovial fluid of patients with rheumatic diseases. Arthritis Rheum 1992;35:1 160-9.

49 Roux-Lombard P, Punzi L, Hasler F, Bas S, Todesco S, Gallati H, et al. Soluble tumor necrosis factor receptors in human inflammatory synovial fluids. Arthritis Rheum 1993;36:485-9.

50 Partsch G, Wagner E, Leeb BF, Dunky A, Steiner G, Smolen JS Upregulation of cytokine receptors sTNF-R55, sTNF-R75, and slL-2R in psoriatic arthritis synovial fluid. J Rheumatol 1998;25:105-10.

51 Tracey KJ, Vlassara H, Cerami A. Cachectin/tumour necrosis factor. Lancet 1989; 1:1122-6.

52 Herrera-Garza EH, Stetson SJ, Cubillos-Garzon A, Vooletich MT, Farmer JA, Torre-Amione $G$. Tumor necrosis factor- $\alpha$ : a mediator of disease progression in the failing human heart. Chest 1999;115:11704.

53 Husby G, Williams RC Jr. Synovial localization of tumor necrosis factor in patients with rheumatoid arthritis. J Autoimmun 1988;1:363-71.
54 Deleuran BW, Chu CQ, Field M, Brennan FM, Katsikis $\mathrm{P}$, Feldmann $M$ et al. Localization of interleukin- $1 \alpha$, type 1 interleukin- 1 receptor and interleukin-1 receptor antagonist in the synovial membrane and cartilage/pannus junction in rheumatoid arthritis. Br J Rheumatol 1992;31:801-9.

55 Saklatvala J. Tumour necrosis factor $\alpha$ stimulates resorption and inhibits synthesis of proteoglycan in cartilage [letter]. Nature 1986;322:547-9.

56 Bertolini DR, Nedwin GE, Bringman TS, Smith DD, Mundy GR. Stimulation of bone resorption and inhibition of bone formation in vitro by human tumour necrosis factors. Nature 1986:319:516-18.

57 Shinmei M, Masuda K, Kikuchi T, Shimomura Y. The role of cytokines in chondrocyte mediated cartilage degradation. J Rheumatol 1989;6/suppl 18):32-4.

58 Dayer JM, Beutler B, Cerami A. Cachectin/tumor necrosis factor stimulates collagenase and prostaglandin $\mathrm{E}_{2}$ production by human synovial cells and dermal fibroblasts. J Exp Med 1985;162:2163-8.

59 Moreland LW. Inhibitors of tumor necrosis factor for rheumatoid arthritis. J Rheumatol 1999;26(suppl 57):7-15.

60 Enbrel $^{\circledast}$ [manufacturer's prescribing information]. Seattle, Washington: Immunex Corporation, 2001.

61 Mouser JF, Hyams JS. Infliximab: a novel chimeric monoclonal antibody for the treatment of Crohn's disease. Clin Ther 1999;21:932-42.

62 Remicade $^{\circledast}$ [manufacturer's prescribing information]. Malvern, Pa: Centocor Inc, 2000.

63 Fredriksson T, Pettersson U. Severe psoriasis-oral therapy with a new retinoid. Dermatologica 1978;157:238-44.

64 Sheehan KC, Pinckard JK, Arthur CD, Dehner LP, Goeddel DV Schreiber RD. Monoclonal antibodies specific for murine p55 and p75 tumor necrosis factor receptors: identification of a novel in vivo role for p75. J Exp Med 1995; 181:607-17.

65 Tartaglia LA, Goeddel DV, Reynolds C, Figari IS, Weber RF, Fendly $B M$, et al. Stimulation of human T-cell proliferation by specific activation of the 75-kDa tumor necrosis factor receptor. J Immunol 1993;151:4637-41.

66 Baseta JG, Stutman O. TNF regulates thymocyte production by apoptosis and proliferation of the triple negative (CD3-CD4-CD8-) subset. $\mathrm{J}$ Immunol 2000;165:5621-30.

67 Zheng L, Fisher G, Miller RE, Peschon J, Lynch DH, Lenardo M. Induction of apoptosis in mature T cells by tumour necrosis factor. Nature 1995;377:348-51. 